\title{
The electrical grid
}

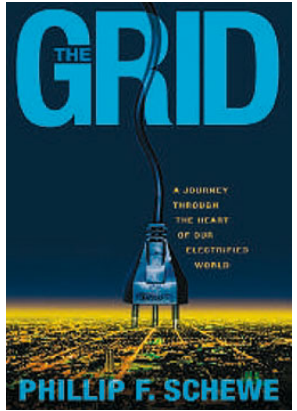

\section{THE GRID: A JOURNEY THROUGH THE HEART OF OUR ELECTRIFIED WORLD BY PHILLIP F. SCHEWE}

Joseph Henry Press: 2007. 311 pp. \$27.95

When I was eighteen I left my home in rural Wales to become an undergraduate at Birmingham University and for the first time I lived in a house with mains electricity. An appreciation of the many advantages electricity brings has stayed with me so I am not one of those who object to electrical pylons striding across green fields. Instead, I am reminded of Stephen Spender's 1933 poem 'The Pylons':

\section{Pylons, those pillars}

Bare like nude, giant girls that have no secrets.

Pylons also appear in Day-Lewis's poem to Auden. Indeed Spender, Day-Lewis, Auden and MacNeice became known as the 'Pylon School', such was the impact of the great electricity grid on our literati.

'The Grid' is an unusual book about an important subject. The author, Phillip Schewe, is the chief science writer at the American Institute of Physics, and a playwright. He describes his book as the first full-length popular book devoted to the development of the power-supply system. It is certainly eminently readable even if, to a British reader, the writing sometimes seems 'folksy' and extravagant.

The author is quite correct to identify the development of the incandescent carbon filament lamp as the launching pad for the electricity grid, and indeed for the electrical age. I regret though that he fails to acknowledge the pioneering work of Britain's Joseph Swan on the development of the lamp, and that he does not emphasise that Edison's Holborn Viaduct electrical scheme, which began operation on 12 January 1882 , was the world's first public supply of electricity from a central steam-generating power plant. (My attempt some years ago to persuade the London authorities to place a plaque on the Viaduct celebrating this achievement were unsuccessful - perhaps I should try again.)

The strength of the book lies in the author's refusal to view all technological advances as being necessarily beneficial to mankind, and he cites repeatedly Henry David Thoreau, Henry Adams, Lewis Mumford and Amory Lovins in support of this thesis. He contrasts Thoreau's rejection of technology at Walden Pond with Faraday's inventions of new electrical technology. He recounts Adams's feeling of helplessness when he entered the Electric Hall of the 1893 Chicago Fair and viewed the electrical machinery, and Schewe is influenced by Munford's essays in the 'New Yorker' on the sociology of technological developments. He admires Lovins, which is reciprocated, and this mutual admiration may be harmful to the balance of the book, particularly on the relative merits of windmills and nuclear power in combating global warming. Schewe is under the impression that American pressurized water reactors are fuelled by metallic uranium rather than the enriched oxide, and this questions his knowledge of nuclear technology.

Perhaps under the influence of Thoreau, Adams and Mumford, Schewe has taken the two great American blackouts of 9 November 1965 and 14 August 2003, due to grid control failures, as indicative of man's over-reliance on technology. He attaches such importance to these events that he has devoted the start of his book and two chapters to an account of the dramatic consequences of the blackouts. But are these events that important? The systems can soon recover control and measures can be taken to lessen the likelihood of a re-occurrence. An infinitely more important example of a highly dangerous impact of technology is the production of greenhouse gases and the prospect of global warming. The failure to discuss this issue in relation to the current political scene in America is in fact the most serious shortcoming of the book. There is only a single mention of the Kyoto Treaty and that in relation to actions by European countries. President Bush's rejection of the Kyoto protocol is not mentioned - indeed one would look in vain at the index to find a single reference to the President, let alone find any comment of his rejection of the evidence of anthropologically induced global warming.

\section{Jack Harris}

J. E. Harris worked for the UK Central Electricity Generating Board for 30 years, and is now Vice-Chairman of British Pugwash.
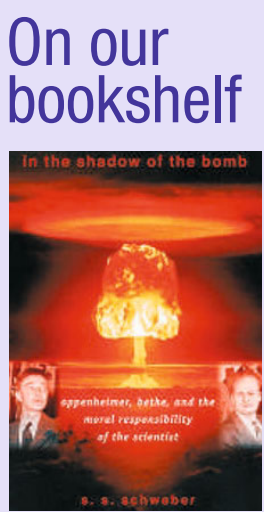

In the Shadow of the Bomb: Oppenheimer, Bethe, and the Moral Responsibility of the Scientist by S. S. Schweber Princeton Univ. Press: 2007. 260 pp. $\$ 18.95$

Having helped to create the ultimate weapon, J. Robert Oppenheimer and Hans Bethe both struggled with the moral fallout. This story describes their divergent approaches.

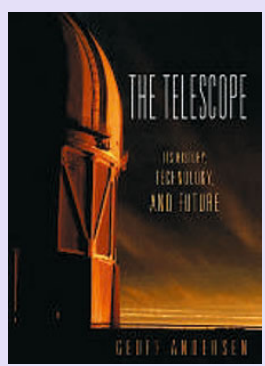

The Telescope: Its History, Technology, and the Future by Geoff Andersen Princeton Univ. Press: 2007. 256 pp. \$29.95

Next year the telescope turns 400. It has become a part of our everyday lives. Besides gathering signals from around the universe, telescopes transmit telecommunications signals and create detailed maps of Earth. 